The socio-adaptive (or "nontechnical") aspects of healthcare including leadership, followership, mentorship, culture, teamwork, and communication are not formally taught in medical training. Yet, they are critical to our daily lives as hospitalists.

The LPD series features brief "pearls of wisdom" that highlight these important lessons.

\title{
Leadership \& Professional Development: Know Your TLR
}

\author{
Sanjay Saint, MD, MPH',2; Vineet Chopra MD, MSc',1*
}

'VA Ann Arbor Healthcare System, Ann Arbor, Michigan; ${ }^{2}$ Division of Hospital Medicine, University of Michigan Health System, Ann Arbor, Michigan.

"Better to remain silent and be thought a fool than to speak and remove all doubt.."

—Abraham Lincoln

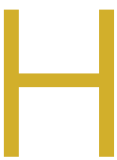

ave you ever been in a meeting with a supervisor wondering when you will get a chance to speak? Or have you walked away from an interview not knowing much about the candidate because you were talking all the time? If so, it might be time to consider your TLR: Talking to Listening Ratio. The TLR is a leadership pearl of great value. By keeping track of how much you talk versus how much you listen, you learn how and when to keep quiet.

As Mark Goulston wrote, "There are three stages of speaking to other people. In the first stage, you are on task, relevant and concise ... the second stage (is) when it feels so good to talk, you don't even notice the other person is not listening. The third stage occurs after you have lost track of what you were saying and begin to realize you might need to reel the other person back in." Rather than finding a way to re-engage the other person by giving them a chance to talk while you listen, ". . . the usual impulse is to talk even more in an effort to regain their interest." 1

When you are talking, you are not listening-and when you are not listening, you are not learning. Executives who do all the talking at meetings do not have the opportunity to hear the ideas of others. Poor listening can make it appear as if you don't care what others think. Worse, being a hypocompetent listener can turn you into an ineffective leader-one who does not have the trust or respect of others.

The TLR is highly relevant for hospitalists: physicians and nurses who do all the talking are not noticing what patients or families want to say or what potentially mistaken conclusions

*Corresponding Author: Vineet Chopra MD, MSc; Email: vineetc@umich.edu; Telephone: 734-936-4000; Twitter: @vineet_chopra.

Received: January 30, 2019; Accepted: January 31, 2019

(C) 2019 Society of Hospital Medicine DOI 10.12788/jhm.3184 they are drawing. Similarly, quality improvement and patient safety champions who do all the talking are not discovering what frontline clinicians think about an initiative or what barriers need to be overcome for success. They are also not hearing novel approaches to the problem or different priorities that should be addressed instead.

Your goal: ensure that your TLR is less than 1. How? Make it a habit to reflect on your TLR after an encounter with a patient, colleague, or supervisor and ask yourself, "Did I listen well?" In addition to its value in monitoring your own talkativeness, use the TLR to measure others. For example, when interviewing a new hire, apply TLR to discover how much patience would be required to work with a candidate. We once interviewed a physician whose TLR was north of $20 \ldots$ we passed on hiring them. The TLR is also helpful for managing meetings. If you find yourself in one with an over-talker (TLR $>5$ ), point to the agenda and redirect the discussion. If it's a direct report or colleague that's doing all the talking, remind them that you have another meeting in 30 minutes, so they will need to move things along. Better yet: share the TLR pearl with them so that they can reflect on their performance. If you're dealing with an under-talker (eg, TLR<0.5), encourage them to voice their opinion. Who knows-you might learn a thing or two.

The most surprising aspect to us about TLR is how oblivious people tend to be about it. High TLR'ers have little idea about the effect they have on people while those with an extremely low TLR (less than 0.2) wonder why they didn't get picked for a project or promotion. Aim for a TLR between 0.5 and 0.7 . Doing so will make you a better leader and follower.

Disclosures: Drs. Saint and Chopra are co-authors of the upcoming book "Thirty Rules for Healthcare Leaders," from which this article is adapted. Both authors have no other relevant conflicts of interest.

\section{References}

1. Goulston M. How to Know If You Talk Too Much. Harvard Business Review. https://hbr.org/2015/06/how-to-know-if-you-talk-too-much. Accessed January 30,2019 . 